\title{
A dança e as pessoas com deficiência visual: uma análise de vinte anos de produção acadêmica brasileira
}

\author{
Dance and visually impaired people: an analysis of twenty years of \\ Brazilian academic production
}

\section{La danza y las personas con discapacidad visual: un análisis de veinte años de producción académica brasileña}

\section{Patricia Andrea Osandon Albarran ${ }^{a}$; ; Daniele Nunes Henrique Silva ${ }^{b} \mathbb{D}^{\mathbb{D}}$; Eva Aparecida Pereira Seabra da Cruz}

${ }^{a}$ Doutora pelo Programa de Pós-Graduação em Processos de Desenvolvimento Humano e Saúde, da Universidade de Brasília (UnB), Mestre em Ciência Política pela UnB, especialista em Gestão de Projetos pela Escola de Administração e Negócios (ESAD). Universidade de Brasília, Brasília, DF, Brasil-E-mail: patricia.osandon@gmail.com

${ }^{\text {b }}$ Graduada em bacharelado e licenciatura em Pedagogia pela Universidade Estadual de Campinas (UNICAMP). Mestre em Psicologia da Educação e Doutora em Educação, pela UNICAMP. Universidade Estadual de Campinas, Campinas, SP, Brasil - E-mail: daninunes74@gmail.com

${ }^{c}$ Graduada em Letras (Bacharelado e Licenciatura em Português) pela Universidade de São Paulo (USP), mestre em Teoria da Literatura pela Universidade de Brasília (UnB) e Doutora em Teoria Literária e Literatura Comparada pela USP. Universidade de Brasília, Brasília, DF, Brasil - E-mail: evaleones@gmail.com

Resumo: Este artigo tem o objetivo de realizar uma revisão bibliográfica de trabalhos publicados em congressos acadêmicos, artigos, dissertações e teses no idioma português publicados e realizados no Brasil, entre os anos 1996 e 2016, sobre o papel da dança na vida da pessoa cega ou com baixa visão. Como resultados da análise realizada a respeito da bibliografia pesquisada, verificou-se que a dança, enquanto arte e atividade que coloca em evidência o movimento e o contato do(a) dançarino(a) com outras pessoas e com o mundo, promove o desenvolvimento de habilidades motoras, espaciais e de locomoção para a pessoa com deficiência visual, bem como contribui para o desenvolvimento de aspectos sociais, psíquicos e do aumento da autoestima. Além desses benefícios, inferidos em muitos dos trabalhos analisados, também se verificou a possibilidade de profissionalização dos(as) bailarinos(as) cegos(as) ou com baixa visão, indicando a centralidade da dança para a inclusão social da pessoa com deficiência visual.

Palavras-chave: Deficiência Visual. Dança. Corpo.

\begin{abstract}
This paper aims to make a bibliographical review of papers published in academic conferences, articles, dissertations and thesis published and conducted in Brazil and in Portuguese language between 1996 and 2016 on the role of dance in the life of blind or low vision person. As a result of the analysis carried out regarding the researched works, it was verified that dance - as an art and as an activity that highlights the movement and the dancer's contact with other people and with the world - promotes the development of motor, spatial and locomotion skills for the visually impaired people, contributing as well to the development of social, psychic and self-esteem issues. In addition to these benefits, inferred in many of the works analyzed, it was also verified the increase of the professionalization opportunities for blind or low vision dancers, indicating the centrality of dance for the social inclusion of the visually impaired person.
\end{abstract}

Keywords: Visual impairment. Dance. Body. 
Resumen: Este artículo tiene como objetivo realizar una revisión bibliográfica de artículos publicados en conferencias académicas, tesis y tesis publicadas y realizadas en Brasil y en portugués entre 1996 y 2016 sobre el papel de la danza en la vida de las personas ciegas o con baja visión. Como resultado del análisis realizado sobre los trabajos investigados, se verificó que la danza, como arte y como actividad que resalta el movimiento y el contacto del bailarín con otras personas y con el mundo, promueve el desarrollo motor, espacial y habilidades de locomoción para las personas con discapacidad visual, que contribuyen también al desarrollo de problemas sociales, psíquicos y de autoestima. Además de estos beneficios, inferidos en muchos de los trabajos analizados, también se verificó el aumento de las oportunidades de profesionalización para los bailarines ciegos o con baja visión, lo que indica la centralidad de la danza para la inclusión social de las personas con discapacidad visual.

Palabras clave: Discapacidad visual. Danza. Cuerpo.

Como citar o artigo:

ALBARRAN, P. A. O; SILVA, D. N. H; CRUZ, E. A. P. S. A dança e as pessoas com deficiência visual: uma análise de vinte anos de produção acadêmica brasileira. Revista de Ciências Humanas, Florianópolis, v. 52, 2018 DOI:

$10.5007 / 2178-4582.2018 .49282$

\section{INTRODUÇÃO}

Entre as discussões atuais que mais vêm ganhando destaque no campo da psicologia do desenvolvimento estão aquelas que tensionam os debates sobre deficiência e suas interfaces com as áreas de educação inclusiva e as diversas artes. Com o objetivo de contribuir para o debate, o presente texto busca realizar uma análise das produções conduzidas no Brasil nos últimos vinte anos que dizem respeito ao papel da dança na vida da pessoa cega ou com baixa visão. A partir do estudo dos trabalhos realizados sobre o tema escolhido, o artigo procura colocar em relação três campos distintos, mas entrelaçados, do conhecimento; quais sejam: a psicologia do desenvolvimento, a inclusão de pessoas com deficiência e o papel da arte nesse processo.

Cabe considerar que a dança profissional clássica foi, durante séculos, estruturalmente desenvolvida para um corpo que é branco, esbelto, fino e não deficiente. Contudo, nas últimas duas décadas, tem merecido destaque o desenvolvimento de trabalhos acadêmicos que tematizam o papel da dança para pessoas cegas e com baixa visão, revelando a importância do debate e a necessidade de se pensar em um corpo que "é constituído de movimento, pensamento, emoção, razão, sentimentos e sonhos, muitos sonhos" (CAZÉ; OLIVEIRA, 2008, p. 01).

O corpo cego, como explicam Cazé e Oliveira (2008), acessa informações por outras vias que não a visão, sendo essa a única diferença que o distingue de um corpo sem deficiência. Para elas, nossa primeira forma de linguagem é o movimento. Assim, é o corpo que protagoniza a linguagem não verbal, em um constante processo de aprendizagem e interação. Quando dançamos, independente de sermos videntes ou não, participamos da construção do conhecimento do movimento, das percepções e das sensações derivadas do corpo e, nele, impressas. Conhecer, portanto, trajetórias desenvolvimentais não hegemônicas de se relacionar com o movimento, via dança, por exemplo, tem 
sido o interesse investigativo de alguns pesquisadores brasileiros, como veremos nos resultados e discussão apresentados neste artigo.

Os estudos sobre deficiência surgiram tardiamente nas ciências humanas e sociais. O assunto, porém, traz desafios para a contemporaneidade, uma vez que não se trata mais de entender a deficiência como uma limitação orgânica, mas como uma "opressão" sobre o "corpo com variações de funcionamento" (DINIZ; BARBOSA; SANTOS, 2009, p. 65). Construiu-se, ao longo da história, a imagem da deficiência como uma desvantagem social, de forma que hegemonicamente ainda prevalecem os discursos que versam sobre o que é normal e o que é patológico.

Atualmente, a avaliação da deficiência, no contexto brasileiro e de muitos países no mundo, pauta-se pela dimensão biopsicossocial da pessoa com deficiência. A Lei n ${ }^{0}$. 13.146, de 6 de julho de 2015 (BRASIL, 2015), ou Lei Brasileira da Inclusão da Pessoa com Deficiência, diz em seu artigo $2^{\circ}$. que:

Considera-se pessoa com deficiência aquela que tem impedimento de longo prazo de natureza física, mental, intelectual ou sensorial, o qual, em interação com uma ou mais barreiras, pode obstruir sua participação plena e efetiva na sociedade em igualdade de condições com as demais pessoas (BRASIL, 2015).

Há dois modelos centrais para a compreensão sobre deficiência, que são o biomédico e o social. Enquanto no modelo biomédico a pessoa com deficiência visual, por exemplo, é considerada como um indivíduo que não enxerga, com destaque para os fatores biológicos, no modelo social as barreiras sociais são criadas pela própria sociedade contra as pessoas com deficiência, de modo que é isso que cria a incapacidade/desvantagem para a vida em sociedade (SASSAKI, 1997). Assim, no modelo social, o corpo passa a ser considerado um espaço em que os discursos discriminatórios existem e devem ser refletidos. Porém, como alertam Diniz (2007), Santos (2008) e Santos, Diniz e Pereira (2010), pensar a partir do modelo social não significa que a pessoa com deficiência não precise ou dispense o cuidado da biomedicina ou da reabilitação, assim como qualquer ser humano pode precisar de atendimento médico ao longo da vida.

\section{METODOLOGIA}

Esta pesquisa apresenta como seu caminho principal uma investigação conduzida em âmbito nacional sobre o que se produziu em termos acadêmicos a respeito da dança em pessoas com cegueira ou baixa visão, entre os anos 1996-2016. A pesquisa foi feita na base integrada da Universidade de Brasília (UnB), que reúne várias fontes de pesquisa, como: o Portal de Periódicos da Coordenação de Aperfeiçoamento de Pessoal de Nível Superior (CAPES)/Ministério da Educação (MEC); e no oasisbr, o portal brasileiro de publicações científicas em acesso aberto do Instituto Brasileiro de 
Informação em Ciência e Tecnologia (IBICT), unidade de pesquisa do Ministério da Ciência, Tecnologia, Inovações e Comunicações (MCTIC). Foi utilizado também, para efeito de ampliação do mapeamento bibliográfico, o Google Acadêmico, de modo a procedermos uma verificação cruzada das referências bibliográficas que foram citadas pelos(as) autores(as) encontrados(as) na pesquisa.

Os trabalhos analisados foram aqueles publicados e realizados no Brasil na forma de comunicações em congressos acadêmicos, artigos, dissertações e teses no idioma português sobre o tema escolhido no período estudado. Para isso, selecionamos para a busca nos locais estabelecidos para a pesquisa os seguintes conjuntos de palavras: deficiência visual e dança; cegueira e dança; baixa visão e dança ${ }^{1}$.

\section{RESULTADOS E DISCUSSÃO: OS ESTUdOS SOBRE A DANÇA E PESSOAS CEGAS E COM BAIXA VISÃO - UM PANORAMA HISTÓRICO}

No período destacado, encontramos vários estudos voltados para as questões sobre corporeidade e movimento da pessoa com deficiência visual que vivencia a dança, como o conduzido por Figueiredo, Tavares e Venâncio (1999a, 1999b). As autoras, a partir de uma abordagem fenomenológica, defendem que o corpo é subjetivo - e, dessa forma, ele é fonte dos nossos sentimentos, pensamentos e ações. A pesquisa de Figueiredo, Tavares e Venâncio (1999a, 1999b) contou com a participação de 13 adultos, com deficiência visual, entre 14 e 50 anos, de ambos os sexos, que estavam vivenciando a dança, tanto de forma amadora quanto profissional.

Na perspectiva apresentada por Figueiredo, Tavares e Venâncio (1999a), não se pode separar a vivência física da emocional quando dançamos, pois ambas fazem parte do mesmo indivíduo. Dessa forma, para as autoras, ao dançar, o indivíduo vivencia uma experiência transformadora que permanece marcada na história pessoal e coletiva. No entanto, Figueiredo, Tavares e Venâncio (1999b) acrescentam que as dificuldades enfrentadas pela pessoa com deficiência ao longo da vida, em contextos como o de trabalho, escola ou lazer, também se repetem na dança, onde elas encontram preconceitos e poucas oportunidades.

Por isso, para Figueiredo, Tavares e Venâncio (1999a, 1999b), a sociedade deve buscar oferecer oportunidades para que a pessoa com deficiência tenha pleno acesso ao mundo da dança. Por envolver vários sentidos simultâneos, com destaque para a audição e o tato, a dança é uma atividade que promove a inserção da pessoa no espaço, tanto em seu sentido mais denotativo de preenchimento

\footnotetext{
${ }^{1}$ Após a busca inicial, excluímos os textos que não tinham como foco central a articulação com o tema da dança para pessoas com deficiência visual, uma vez que outras atividades artísticas (tais como artesanato ou música) ou outras deficiências não são objetos de estudo desta pesquisa. Também não consideramos textos que abordavam a dança na infância da criança com deficiência visual, nem monografias ou trabalhos publicados sem referência de origem ou não focados no tema da dança para pessoas com deficiência visual.
} 
de um lugar, como enquanto metáfora de preenchimento de um vazio e um estar no mundo. Assim, não apenas na dança enquanto atividade artística, mas também em todas as áreas da vida humana, as autoras reforçam que a pessoa com deficiência que dança deve ser vista como um sujeito, com suas potencialidades respeitadas (FIGUEIREDO; TAVARES; VENÂNCIO, 1999a, p.71).

Segundo Figueiredo, Tavares e Venâncio (1999a), a dança configura-se como meio de aprimoramento da experiência com o mundo. Como explicam as autoras:

A Dança é uma arte e, como tal, nos permite transformar cada momento em um ato criativo. Por meio dela, podemos entender o instante e, daí, perceber a transformação da vida. Na Dança, a essência é sempre original, pois somos um corpo em presença no mundo. Somos todos dançarinos, pois expressamos pelo corpo aquilo que somos. A Dança não distingue nem oprime ninguém — nós é que o fazemos (FIGUEIREDO; TAVARES; VENÂNCIO, 1999a, p. 72).

A partir dos trabalhos realizados com pessoas com deficiência visual, Figueiredo, Tavares e Venâncio (1999a, 1999b) afirmam que puderam perceber o desenvolvimento da expressão corporal e o prazer do movimento nos participantes, bem como a construção de interações sociais. Para as autoras, a dança permite que sejam traçados vários caminhos, como, por exemplo, a percepção e a concepção de uma cidadania do corpo, com regras compartilhadas, recriadas e discutidas no próprio grupo que a pratica. Em tal contexto, "cada corpo tem o dever e o direito de escrever sua própria história" (FIGUEIREDO; TAVARES; VENÂNCIO, 1999a, p. 72).

Outro estudo voltado para a importância da dança em relação à corporeidade e à ampliação do movimento foi conduzido por Francisco (2013). A autora contextualiza e reúne resultados de trabalhos desenvolvidos sobre dança arquetípica, psicomotricidade e biodanza ${ }^{2}$ para adultos (homens e mulheres) com e sem deficiência visual. Entre os temas de estudo da autora estão questões como a corporeidade com ênfase na expressividade, a espontaneidade, a liberação do movimento, a interioridade e o inter-relacionamento entre pessoas com e sem deficiência visual, buscando-se estabelecer uma visão transdisciplinar da relação entre arte e educação.

Com a finalidade de compreender mais a respeito da percepção sensorial e dos modelos pelos quais pessoas cegas e com baixa visão desenvolvem questões como a espacialidade e a corporeidade, Francisco (2013) pontua que a dança arquetípica e a biodanza possibilitam que seus praticantes se expressem em uma linguagem simbólica. Entre os resultados encontrados após os estudos com pessoas com deficiência visual e a dança, Francisco aponta o aumento da mobilidade e da integração entre o grupo, da sensibilidade interpessoal e maior consciência da corporeidade e da espacialidade.

\footnotetext{
${ }^{2}$ Francisco (2013, p. 39) explica que, "praticamente em posição oposta à Dança Clássica, por mim praticada no início de minha vida artística, a Dança Arquetípica e a Biodanza privilegiam a espontaneidade dos movimentos que brotam quase sempre de instâncias interiores designadas por Jung como Inconsciente Coletivo, Arquétipos, Sombra e Self”.
} 
Também no período selecionado de pesquisa bibliográfica, há o estudo de Golin (2002), que traz o relato de atividades de dança realizadas na Associação Catarinense de Integração do Cego, em Santa Catarina (SC). Norteada pela questão “qual o significado que a dança tem em sua vida?”, a autora realizou uma pesquisa com seis pessoas com cegueira congênita, de ambos os sexos, entre 17 e 26 anos, que participavam de aulas de dança e, especialmente, expressão corporal. Golin (2002) explica que, na associação pesquisada, o movimento é baseado em três referenciais teóricos da dança: Laban, Body-Mind Centering e Contact Improvisation ${ }^{3}$.

Em relação ao funcionamento das aulas, Golin (2002) explica que, como atividade inicial, os alunos têm a possibilidade de conhecer o local - algo importante para que possam perceber como estão organizados os objetos no ambiente, bem como para que possam ter noção do espaço físico no qual estão dançando. Após essa primeira etapa, os alunos são incentivados a realizar movimentos e descrevê-los para a turma. Depois, iniciam a aula e fazem movimentos e exercícios corporais e de dança, com a supervisão de uma professora. Enquanto expressão rítmica do corpo, Golin (2002) afirma que a dança traz benefícios físicos, sociais e psicológicos para seus participantes. Para a autora, além de permitir ao indivíduo que se expresse melhor, a dança colabora para o desenvolvimento da socialização, da expressão de emoções e sentimentos e da consciência corporal, de modo a mediar o autoconhecimento e, especialmente, a relação com o outro.

Assim, a dança ganha um caráter ainda mais importante para a pessoa com deficiência visual, uma vez que os benefícios alcançados por sua prática produzem, além de tudo, a independência e a conquista de uma maior mobilidade. Segundo Golin (2002), a partir da pesquisa conduzida pode-se apontar como benefícios da dança uma melhor consciência corporal e as novas possibilidades de movimentos e de desenvolvimento da criatividade. Embasada nos resultados da pesquisa, a autora reforça que a dança pode contribuir para a melhoria de aspectos físicos, sociais e psíquicos, e, também, para o aumento da autoestima e da inclusão social.

Os benefícios corporais e sociais são apenas alguns dos proporcionados pela dança. Outros estudos, como o realizado por Valla, Porto e Tolocka (2006), destacam o potencial da dança também para o movimento e para o equilíbrio da pessoa com deficiência visual. Valla, Porto e Tolocka (2006) relatam um estudo de caso com uma aluna de 27 anos de idade com deficiência visual, em Campinas (SP). O estudo, conduzido pelas autoras, conta com um programa que compreende 12 aulas de

\footnotetext{
${ }^{3}$ O nome Laban vem de Rudolf Von Laban (1879-1958), que considerava o movimento a nossa primeira forma de linguagem. Já para a terapeuta educacional Bonnie Bainbridge Cohen, que desenvolveu o método denominado BodyMind Centering, corpo e mente têm profunda relação, sendo que o corpo traz manifestações e expressões da mente. Steve Paxton, por sua vez, criou o Contact Improvisation, que tem como um de seus fundamentos a relação entre toque e equilíbrio entre duas pessoas (GOLIN, 2002).
} 
sapateado ${ }^{4}$. Nele, primeiramente, se estabelece o nível de aprendizagem nas categorias inicial, elementar e avançada, a partir de informações verbais e táteis. Este último procedimento, relatam as autoras, permitiu que a aluna percebesse os movimentos em seu próprio corpo e levava em consideração o que era expresso em palavras para a execução dos movimentos. Além disso, conforme foi demonstrado na pesquisa, o ensino do sapateado, especialmente para uma pessoa com deficiência, requer a execução de passos e exercícios com informações verbais bastante claras, detalhes dos movimentos e posições das pernas e dos pés, além de trabalhos com ritmos e estímulos proprioceptivos.

Segundo as autoras, no sapateado, depois que o movimento é explicado verbalmente, o(a) aluno(a) deve executar o passo da maneira ensinada, permitindo-se também que a pessoa com deficiência visual perceba o movimento do professor pela informação tátil. Para o ensino da dança para uma pessoa cega ou com baixa visão, o professor deve estar em interação e sintonia com o seu aluno (VALLA; PORTO; TOLOCKA, 2006).

Segundo Valla, Porto e Tolocka (2006), é o movimento o responsável por criar o elo entre o ser humano e sua corporeidade e subjetividade, de modo que as experiências corporais vivenciadas com a dança se tornam repletas de significados. As autoras verificaram que, após as aulas, a aluna conquistou mais independência e segurança nos movimentos; maior coordenação motora, equilíbrio e ritmo; e, também, uma nova vivência da corporeidade, de modo que passou a se ver como um sujeito de direitos.

Percebemos que o sapateado pode ser mais uma forma de aprendizagem motora para a pessoa com deficiência visual e que através dele é possível perceber e conquistar mudanças em suas possibilidades motoras e que a proposta de ensino proporcionou mudanças na execução das atividades, tornando os movimentos mais habilidosos. Além disso, acreditamos que a dança pode ser um espaço possível para a vivência da corporeidade, permitindo expressar o que somos, na tentativa de buscar significados e significações para nossa existência (VALLA; PORTO; TOLOCKA, 2006, p. 09).

Outros autores buscaram compreender a influência que a dança exerce no equilíbrio estático e dinâmico de pessoas com deficiência visual. Entre esses autores estão Silva, Ribeiro e Rabelo (2008), que realizaram uma pesquisa com a participação de trinta pessoas cegas ou com baixa visão, com idade entre 12 e 60 anos, de ambos os sexos, e separadas em dois grupos. Enquanto um dos grupos participou de um programa de dança durante oito semanas com duas aulas semanais, o outro se vinculou a um programa de atividades manuais.

\footnotetext{
${ }^{4}$ Conforme Valla, Porto e Tolocka (2006, p. 01), "o sapateado americano é uma modalidade de dança que se faz através de ritmos e sons produzidos por movimentos de pernas e pés, com o auxílio de plaquinhas de metal parafusadas nos sapatos", estando o ritmo marcado também pelo som produzido nos movimentos coordenados pela pessoa que dança.
} 
Para os dois grupos, foi definido o mesmo parâmetro em relação ao equilíbrio estático e dinâmico no início das atividades. Depois de oito semanas, Silva, Ribeiro e Rabelo (2008) compararam o desempenho dos grupos em relação aos ganhos no equilíbrio estático e dinâmico, constatando que o grupo que teve contato com a dança teve ganhos mais significativos na comparação com o outro. Para os autores, a dança, além de colaborar para o desenvolvimento das capacidades físicas, cognitivas, intelectuais e emocionais da pessoa cega ou com baixa visão, possibilitou o favorecimento da autonomia e do domínio do corpo.

Outro estudo que discutiu a importância da dança para o movimento e noção de corporeidade da pessoa com deficiência visual foi realizado por Romão (2011). Em sua dissertação de mestrado, Romão (2011) buscou pesquisar como a dança circular atua na vida de pessoas com deficiência visual. Dialogando com princípios vigotskianos, a autora utilizou-se da pesquisa-ação com oito adultos com deficiência visual, sendo o campo empírico desenvolvido no Instituto de Educação e Reabilitação de Cegos de Natal (RN). Há vários elementos que Romão aponta como relevantes para o aprendizado dos alunos, como o toque na dança e na movimentação corporal, seja entre colegas ou com o professor, de modo a perceber a demonstração do movimento. Além disso, há a utilização de outro recurso tátil: a demarcação do espaço - um círculo - no chão por meio do uso de fitas amarelas. Enfatiza-se também o uso do recurso da descrição verbal, com a qual se explica o que está sendo realizado na dança, fazendo com que a pessoa cega ou com baixa visão apreenda os conceitos mediante o uso das palavras antes de internalizá-los e incorporá-los a seus movimentos e gestos.

A partir da pesquisa que envolveu a prática de encontros com a dança circular e entrevistas semiestruturadas, Romão (2011, p. 06) aponta que a dança circular teve "influência na ampliação do movimento dos sujeitos da pesquisa, no desenvolvimento de uma melhor percepção de si e das suas capacidades, nas relações Eu/Outro, Eu/Mundo, as quais se dão num contexto de diferenças". Nesse sentido, a autora reforça que a dança envolve um processo de compreensão não apenas sobre o próprio corpo, mas também sobre o corpo do outro, o que traz benefícios para pessoas com e sem deficiência.

Perez et al. (2013) realizaram uma pesquisa do tipo qualitativa, exploratória e descritiva com seis pessoas com deficiência visual, sendo duas com baixa visão e quatro cegos, todos adultos e de ambos os sexos, da cidade de Santa Maria (RS). O objetivo central do trabalho foi compreender o papel da dança na vida dessas pessoas, especialmente em relação às habilidades motoras, espaciais, emocionais e de locomoção. Perez et al. (2013) construíram a pesquisa a partir de observações sistemáticas e um roteiro de entrevistas semiabertas, com um plano de intervenção de diferentes ritmos de dança.

Entre os aspectos centrais do estudo de Perez et al. (2013) está a importância do tato, apontado pelas autoras como uma forma diferente de sentir e ver o movimento do corpo. Para Perez et al. (2013), a sensação do toque e o exercício do equilíbrio no contato com o outro durante a dança 
permitem descobrir mais sobre os movimentos e percepções de cada corpo dançante. Além disso, foi possível observar que, somada ao tato, a audição possibilita ao ser humano "“sentir' o ritmo musical” (PEREZ et al., 2013, p. 793), sendo possível afirmar que, quando corpos dançam, eles se comunicam.

As autoras explicam que os movimentos realizados na dança possibilitam aos dançarinos tenham deficiência ou não - o aumento de aspectos importantes como: flexibilidade, elasticidade, deslocamento, resistência e, em especial, o equilíbrio. A partir da pesquisa, Perez et al. (2013) afirmam que houve em cada participante uma melhora significativa em relação ao equilíbrio, domínio do corpo e noção de espaço. Em termos coletivos, uma vez que a pesquisa foi realizada com um grupo, as autoras também verificaram a ampliação das experiências sociais, em razão das atividades e dos exercícios propostos em conjunto.

Conclusões similares ao trabalho de Perez et al. (2013) foram obtidas na pesquisa realizada por Zaniboni e Rodrigues (2013), que apontam como a dança pode ser fundamental no processo de conscientização corporal, melhoria do equilíbrio e aumento da consciência da realização pessoal da pessoa com deficiência visual. A pesquisa de Zaniboni e Rodrigues (2013) detalha o processo de ensino e aprendizagem entre um professor de dança de salão e uma aluna de 52 anos com deficiência auditiva (congênita) e visual (a partir dos 20 anos, em razão de uma retinose pigmentar). Zaniboni e Rodrigues (2013) defendem que a dança é fundamental para o desenvolvimento de habilidades físicas, psicológicas, sociais e comunicativas.

Entre os aspectos mais importantes do estudo de Zaniboni e Rodrigues (2013) está a centralidade da interação entre o professor e a aluna. O diálogo entre professor e aluna se dava a partir de uma técnica utilizada por ele, na qual se utilizava a língua de sinais na palma da mão esquerda da aluna, por meio da percepção tátil-cinestésica manual e digital. Outra estratégia adicional utilizada pelo professor ocorria quando ele pedia à aluna que colocasse as mãos na caixa de som de modo a sentir a vibração sonora.

As aulas de dança realizadas por um período de seis meses, com aulas todos os dias, possibilitaram, conforme os autores, que a aluna conquistasse mais agilidade física e equilíbrio, além de melhoria na postura corporal e na autoconfiança. Após as aulas, a aluna passou a se assumir como um corpo dançante; uma bailarina.

Nesse sentido, Zaniboni e Rodrigues (2013) apontam que a dança de salão deve ser ensinada a partir de uma perspectiva que interpreta o ser humano como um ser que vai muito além do biológico. Esse ser é também psíquico e social, de modo que, dentro desse entendimento, é possível atingir muito mais do que técnicas e reprodução de passos: alcança-se também a superação física, emocional e social, além de contribuir para a inclusão e a realização pessoal.

Em uma perspectiva educacional, entre os estudos pesquisados encontramos Rocha e Lima (2010, 2011, 2012), que também estudam a relação entre dança e deficiência visual. Pensar a dança 
no contexto educacional, conforme as autoras, implica pautar-se pela valorização da vivência dos movimentos do cotidiano do sujeito, na significação dos movimentos que são vivenciados na dança, na criação individual e coletiva de movimentos e sua autenticidade, na formação estética e, por fim, na apresentação artística.

Em 2010, por exemplo, Rocha e Lima (2010) conduziram uma pesquisa-ação com diário de campo, observação participante, grupo focal, história de vida e vivências práticas com duas jovens de 16 anos com cegueira congênita. Para a realização da pesquisa, Rocha e Lima (2010) contaram com a participação das jovens em intervenções planejadas de dança. As autoras indicam como elementos significativos da pesquisa a consciência corporal, a expressividade, a improvisação, a composição coreográfica, o repertório e o vocabulário de movimento. A partir do estudo, Rocha e Lima (2010) pontuam que um dos elementos centrais no ensino da dança para uma pessoa com deficiência visual é a corporeidade, uma vez que pode trazer contribuições para as vivências de um indivíduo, que poderá construir sua singularidade e intencionalidade.

\section{ARTE-OFÍCIO, DANÇA E AS PESSOAS COM CEGUEIRA OU BAIXA VISÃO}

Entre os anos de 1996 e 2016, período selecionado para análise na elaboração deste artigo, também encontramos pesquisas sobre a arte e a dança para a pessoa com deficiência visual com ênfase no processo de profissionalização dos bailarinos. Almeida (2012), por exemplo, traça um mapeamento nacional de iniciativas de dança para pessoas com deficiência visual, focalizando seu trabalho em duas instituições profissionais de dança, uma em São Paulo e outra em Santa Catarina. Para a realização do trabalho, Almeida (2012) baseou-se em produções acadêmicas das profissionais responsáveis pelos dois grupos, além de entrevistas semiestruturadas e observação de vídeos de espetáculos.

Com base no levantamento realizado, Almeida (2012) aponta que, apesar de uma quantidade significativa de trabalhos em dança com pessoas com deficiência realizados em todo o Brasil, foram identificadas poucas iniciativas de dança específicas com a participação de pessoas com deficiência visual. Conforme a autora, no início da década de 90 é que começaram a surgir as primeiras propostas brasileiras em dança inclusiva, exatamente quando o paradigma da inclusão social ganha ênfase no país.

A partir desse cenário - de poucas iniciativas de dança para pessoas com deficiência visual -, entre os autores com mais textos nacionais e internacionais publicados sobre dança e cegueira está Freire (1999, 2000, 2004, 2004/2005 entre outros), que trabalha desde 1998 com um grupo de dança contemporânea entre dançarinos visuais e não visuais, na Associação Catarinense de Integração do Cego (ACIC). 
O mundo da dança era, conforme Freire (1999), um local em que apenas os corpos considerados perfeitos - tanto em relação às ausências de deficiências quanto em relação aos padrões corporais do balé clássico - poderiam dançar. Nesse sentido, a dança contemporânea representou uma ruptura na tradição clássica da dança.

\begin{abstract}
Quando falamos em dança, cada um de nós pode pensar em vários tipos de dança [...]. Quando nos referimos à dança para a pessoa cujo corpo apresenta uma deficiência, a primeira ideia que talvez passe pela nossa cabeça é a dança terapêutica, ou a dança expressiva ou livre, usada geralmente para se "soltar". Mas, pergunto, será que o corpo diferente está destinado a dançar só certos tipos de dança? Será que, por trás da dança livre, não se esconde o fato de não termos formação adequada para ensinar dança para essas pessoas? Em nome da boa ação, muitas vezes as expomos a situações que poucos de nós nos colocaríamos voluntariamente (FREIRE, 1999, p. 81).
\end{abstract}

Em 2000, outro estudo conduzido por Freire discute a relação entre dança e deficiência. Tendo como ponto de partida as perguntas "Que corpo pode constituir o dançarino?" e "Que movimento pode constituir a dança?", Freire (2000, p. 01) propôs um estudo a partir de atividades de dançaeducação para cegos, ocorridas entre agosto de 1998 e dezembro de 1999, para um grupo de 30 jovens e adultos com deficiência visual, bem como dez pessoas com cegueira de um grupo de teatro. A coleta de dados do estudo de Freire (2000) envolveu entrevistas, registro das aulas de dança em videoteipe e a evocação livre de palavras pelos dançarinos. Como pontua Freire (2000), o objetivo central do estudo foi o de pensar o movimento, por meio do contexto da dança, para algo além do conceito de orientação e mobilidade.

Freire (2000) explica que entre os benefícios da dança-educação está o fato de que ela está mais centrada no processo do que no produto, de modo que o aluno e o professor podem compreender o próprio movimento do corpo. Tendo como questionamento central o que é a dança para os participantes do grupo de dança-educação, Freire explica que, para eles, a dança vai muito além de uma atividade de descontração e diversão: é também uma possibilidade de liberação do corpo, de movimento e de terapia.

A relação direta entre cegueira e escuridão, por exemplo, pode trazer graves equívocos; a vida sem visão costuma ser negligenciada e repleta de incompreensões. Como explica Freire (2004/2005), as reações de pena ou simpatia extremada são perigosas, uma vez que causam mais exclusão. Nesse sentido, para a autora, os dançarinos cegos estão proporcionando às companhias de dança e aos coreógrafos a possibilidade de potencializar as atividades criadoras, provocativas e desafiadoras (FREIRE, 2004/2005).

De fato, a dança voltada para a pessoa com deficiência visual tem se transformado numa possibilidade de profissionalização tanto em âmbito nacional quanto internacional. Bianchini (2011), por exemplo, explica que algumas especificidades e considerações são necessárias para ensinar a 
dança a uma pessoa cega ou com baixa visão. A partir do processo de ensino e aprendizagem do balé clássico, a autora reforça a importância, para uma pessoa cega ou com baixa visão, da propriocepção tátil, das explicações verbais e do compartilhamento de experiências entre as bailarinas.

Segundo Bianchini (2011), o método de ensino envolve o aproveitamento das experiências que a pessoa cega ou com baixa visão tem até o momento em que começa a aprender. Além disso, os movimentos devem ser ensinados a partir de brincadeiras, histórias ou elementos concretos.

Quando vou ensinar um passo, por exemplo, eu preciso primeiro mostrar o movimento das pernas, depois dos braços, depois da cabeça e por fim tudo junto na contagem e no ritmo da música. Depois de ensinar todas as alunas, ensaiamos o passo inúmeras vezes para que todas as alunas dancem ao mesmo tempo e no mesmo compasso coreográfico (BIANCHINI, 2011, p. 40).

Bianchini (2011) explica que o papel do professor de dança deve ser o de incentivar o desenvolvimento de potencialidades do aluno, facilitando o processo de aprendizagem. Como explica a autora, muitas vezes os professores não ensinam tudo o que um aluno com deficiência visual poderia aprender, pois, por não saberem ensinar, não buscam alternativas para que isso possa acontecer. Tratase, conforme defendido por Vigotski (1997), de procurar rotas alternativas de aprendizagem para as situações em que o desenvolvimento segue um curso diferenciado.

Desse modo, ao ensinar a dança clássica para uma pessoa com deficiência visual, o professor deve investir mais tempo no processo de ensino-aprendizagem, embora, como acrescenta Bianchini (2011), após os passos terem sido aprendidos e assimilados, o processo se assemelhe ao de uma bailarina sem deficiência. Somado ao papel do professor, a autora destaca a importância do papel do aprendizado compartilhado entre as bailarinas que detêm mais conhecimento em relação àquelas que estão aprendendo, de modo que uma possa ensinar a outra em relação aos passos e demais aspectos da dança. Percebemos, assim, que o professor que ensina a dança a uma pessoa com deficiência visual deve considerar que há muitas possibilidades de aprendizagem, entre elas o compartilhamento de informações entre colegas de dança.

Ainda no campo da dança profissional, foi conduzida uma pesquisa de cunho qualitativo e de inspiração etnográfica com um grupo de dançarinos com e sem deficiência visual - Potlach Grupo de Dança, projeto de extensão da Universidade Federal de Santa Catarina. Na investigação, Mayca (2008) buscou compreender como dançarinos cegos julgam esteticamente seu trabalho artístico e a relação que estabelecem durante o processo com a criação e com a imaginação. Em outra etapa da pesquisa, foi observado o modo como crianças e adolescentes sem cegueira de uma escola pública percebem a dança contemporânea. Para isso, a autora entrevistou os dançarinos e analisou os textos e desenhos produzidos pelas crianças e conversou com os adolescentes após a exibição de um vídeo do grupo de dançarinos, além de ter realizado a observação participante. 
Quando decidiu levar a dança realizada pelos dançarinos participantes da pesquisa para os estudantes, conduzindo as investigações de tal experiência por meio de entrevistas semiestruturadas, desenhos e a exibição do vídeo-dança "Quatro", Mayca (2008) tinha como objetivo colocar as crianças e adolescentes em contato com a dança contemporânea, realizada por corpos considerados diferentes no palco. No entendimento da autora, a proposta foi feita no sentido de promover a reflexão e a experiência estética nos estudantes, pois, segundo ela, para gostar de algo, é preciso conhecer antes.

Mayca (2008) traz alguns depoimentos das crianças e adolescentes participantes da pesquisa:

Foi bem interessante! Apesar de tudo, eu aprendi uma coisa com essa dança, que não é só uma pessoa normal (grifo nosso) que sabe dançar. Pessoas com deficiência também sabem. Você devia passar para outras turmas de dança. Para eles aprenderem, que a gente também pode aprender a dançar mesmo que seja difícil, já que as pessoas cegas aprendem. Isso é um exemplo para todo mundo. (Eduardo, nome fictício, 16 anos) (p. 51).

Eu gostei, porque eu vi os cegos superando todas as dificuldades da dança, então eu quero que eles continuem assim, e que mais cegos entrem para poder aprender essas danças. (Cristiano, nome fictício, 11 anos) (p. 54).

Mayca (2008, p. V) explica que o julgamento estético está mais conectado "ao sentir do corpo em sua totalidade, à imaginação, ao diálogo com o outro, do que à determinação biológica, vinculada ao ter ou não o sentido da visão". Diante disso, a autora explica que a imaginação e, portanto, a criação de mundos alternativos em relação àquele em que se vive no cotidiano, se configura como uma possibilidade de exercício de superação do preconceito e da construção de uma consciência de que a pluralidade humana pode existir sem julgamentos e condenações. Durante as entrevistas, a autora explica que surgiu a importância da imaginação no julgamento estético, bem como da criação da imagem e da produção dela por meio das nossas experiências vividas - centralmente - na relação com o outro. Mayca explica que é a partir do diálogo com o outro que são recriadas as nossas imagens, de modo a influenciar diretamente os nossos julgamentos estéticos (MAYCA, 2008).

Outra pesquisadora interessada em compreender como ocorre a profissionalização de bailarinos com deficiência visual é Melo (2010), que conduziu um estudo a partir das vivências corporais de bailarinos do Projeto "Passos para Luz", do Centro de Dança Ana Unger, que existe desde 2003. Quando o estudo foi realizado, havia no grupo pesquisado pela autora cinco alunos com baixa visão, entre 20 e 50 anos, sendo apenas um do sexo masculino (MELO, 2010).

O estudo de Melo (2010) considera quais foram as reflexões dos bailarinos e da professora do grupo, com foco no gesto como forma de expressar a comunicação e a corporeidade na dança. Para a autora, bailarinos não videntes podem expressar-se com beleza no gesto: para eles, a arte da dança

\footnotetext{
${ }^{5}$ Disponível no endereço https://www.youtube.com/watch?v=9JXwyqTfxmg.
} 
acontece a partir de outros sentidos. Deve-se considerar, conforme Melo (2010), que os gestos executados no dia a dia têm um caráter utilitário e se diferenciam dos gestos dançados, que têm caráter simbólico e se revestem de características próprias da arte.

Melo (2010) detalha o funcionamento do grupo, bem como a metodologia utilizada para o ensino da dança pela professora. Segundo a autora, a metodologia para o ensino da dança para os bailarinos não videntes veio a partir da própria experimentação corporal e da troca entre todo o grupo, envolvendo tanto alunos quanto a professora. No início, o processo de ensino e aprendizagem no grupo ocorreu por meio das técnicas do balé clássico, especialmente com o objetivo de se alcançar o desenvolvimento da postura e noções de lateralidade, equilíbrio e orientação espacial. Após esse momento, o grupo começou a trabalhar outros estilos de dança e de construção de movimentos. Além disso, quando o grupo se apresenta, o chão costuma ser marcado pela professora com fitas em alto relevo, em forma de "x", para que os bailarinos possam sentir com os pés as marcações e possam se localizar no palco.

Além disso, Melo (2010) destaca como ocorre a comunicação no grupo pesquisado. O primeiro dos três níveis é a informação verbal, momento em que a professora explica aos alunos detalhadamente o que deverá ser realizado em aula. Em um segundo momento, a professora toca o corpo do aluno, explicando os movimentos que não foram entendidos e, por fim, os alunos vivenciam a oportunidade de tocar o corpo da professora enquanto ela faz o movimento, caso não tenham entendido o movimento nas etapas anteriores.

Após acompanhar as aulas, Melo (2010) afirma que os bailarinos do grupo passaram a dominar as técnicas do balé clássico, atingindo maior complexidade em relação aos movimentos realizados. A autora chama a atenção para o fato de que a exteriorização do gesto pelo bailarino com deficiência visual acontece de modo diferente daquele que é vidente. No caso do bailarino com deficiência visual, ele expressa o gesto sem vê-lo; sem ter o movimento mediado pela visão. Apesar disso, como reforça a autora, o fato de os movimentos em cena serem visualizados somente pelo público não significa que o bailarino não sinta a reação da plateia, pois o fenômeno artístico acontece.

[...] a dança é um espetáculo de percepção visual, mas que nesse caso, é exercida por pessoas que não enxergam a própria dança. Isto prova, então, que bailarinos não-videntes não estão impedidos de praticar a dança como forma de arte, apenas são desprovidos da contemplação visual da expressão artística que realizam (MELO, 2010, p. 08).

Além de Melo (2010), também foi realizado outro trabalho como um desdobramento das ações do Projeto "Passos para Luz", por Mota (2014). A autora conduziu um estudo de caso de uma bailarina com deficiência visual com o propósito de pesquisar como ocorria a construção cênica da referida bailarina, de modo articulado ao processo de criação artística. 
Mota (2014), que também procurou compreender como uma plateia com deficiência visual vivencia o espetáculo, reuniu um diretor de cena (que acumulava as funções de dramaturgo e diretor musical), uma coordenadora/coreógrafa/produtora, um preparador corporal, uma iluminadora e a bailarina (intérprete-criadora e produtora do espetáculo). Também fizeram parte da composição da pesquisa quatro pessoas com deficiência visual, que formavam parte de uma plateia experimental. O estudo de Mota (2014) foi conduzido com registros audiovisuais, fotográficos e escritos, bem como entrevistas não estruturadas e depoimentos da equipe participante de um dos espetáculos do grupo.

$\mathrm{Na}$ pesquisa, a autora explica que, embora a equipe tenha conduzido uma tessitura colaborativa e não linear do espetáculo, em uma concepção de criação como rede, a partir de discussões, reflexões e experimentações, o estudo teve como recorte o processo de criação da bailarina. Desse modo, a deficiência visual da bailarina foi levada em consideração na criação e na estruturação do espetáculo, cujo título foi “O Seguinte Olhar”. Para isso, a equipe buscou uma história que pudesse ser contada coreograficamente e que estivesse relacionada ao sentido da visão. O diretor do trabalho sugeriu, então, a Lenda do Guaraná', "por tratar simbolicamente os olhos, que, ao perderem sua função perceptiva, dão frutos que podem alimentar e fortificar o corpo". (MOTA, 2014, p. 03)

Após a definição das cenas propostas pela equipe, foram levantadas questões sobre o processo criativo, os elementos cênicos e a plateia:

[...] como serão apresentados coreograficamente, por uma única bailarina, todos os personagens? De que maneira essa intérprete poderia lidar com a necessidade da simultaneidade interpretativa de duas ou mais personagens? Que tratamento seria dado, cênica e coreograficamente, aos diálogos existentes? Quais artifícios deveriam ser utilizados no sentido de resolver a narrativa, transpondo-a para a cena sem utilização da palavra? Como a plateia deficiente visual poderá ter acesso ao que for produzido? Que elementos cênicos poderão ser utilizados para a criação coreográfica com a bailarina deficiente visual? (MOTA, 2014, p. 05)

\footnotetext{
6 “Icuamã (Ikuamã), *Ocumató (Okumáató) e Onhiamuaçabê (Onhiámuáçabe) eram irmãos. Ciumentos, os dois irmãos de Onhiamuaçabê não queriam que ela se casasse. A jovem conhecia todas as plantas e seus usos e era dona do Noçoquém, um lugar encantado no qual havia plantado uma castanheira. Um dia, uma cobrinha que a queria como esposa, ficou no seu caminho e a tocou levemente numa das pernas, engravidando-a. A mitologia indígena afirma que para uma mulher engravidar bastava ser tocada por homem, animal ou planta que a desejasse como esposa. Furiosos, os dois irmãos a expulsaram e se apoderaram do Noçoquém. Nasceu um curumim bonito e forte. E, mal aprendeu a falar, o menino começou a desejar os frutos da castanheira que sua mãe plantou. O Noçoquém, no entanto, estava sob a guarda da cutia, da arara e do periquito, que tinham ordens de matar quem ali encontrassem. Um dia, quando o menino se deliciava com os frutos, os guardas o mataram. Quando a mãe chegou, já era tarde. Desesperada, ela jurou dar continuidade existência do filho e enterrou seus olhos. A planta que nasceu do olho esquerdo não prestou, era o guaraná-rana, o falso guaraná; do olho direito, é que nasceu o verdadeiro guaraná. A planta do guaraná foi crescendo. Depois de um tempo, da cova onde o menino foi enterrado, começaram a sair alguns animais. No final saiu um menino - o filho de Onhiamuaçabê que ressuscitou. Era o primeiro índio da tribo dos Maués, que se consideram 'os filhos do guaraná'”. (Resumo da lenda colhida e publicada por Nunes Pereira em Os índios Maués, RJ, 1954). Disponível em: $<$ http://www.telessaude.uerj.br/colorindoe-movendo/colorindo/material/lendas/guarana>. Acesso em: 16 dez. 2017.
} 
De modo a elaborar sugestões de procedimentos que dessem conta das dificuldades elencadas, por meio do uso da improvisação, a bailarina participante da pesquisa foi orientada a trabalhar separadamente cada uma das nove cenas da Lenda do Guaraná, com o objetivo de fazer proposições iniciais sobre como se daria a composição corporal e coreográfica dos personagens do espetáculo. Para isso, o preparador corporal orientou a bailarina para a desarticulação corporal, por meio da exploração de vários movimentos e do espaço, bem como com a possibilidade de outras partes do corpo serem focadas, expandindo a consciência do próprio corpo. Mota (2014) traz o depoimento do preparador corporal da bailarina participante do estudo:

Os princípios que busquei trabalhar foram: desarticulação corporal, exploração do espaço, os planos, foco e experimentação corporal a partir de sensações opostas de corpo tenso, corpo relaxado. Conscientização corporal quando eu pedia que ela tocasse, que percebesse o corpo dela através do tato, tocasse o máximo de partes do corpo que ela podia, áreas que normalmente a gente não toca, como: o sovaco, área de trás do cotovelo, atrás do joelho. Então essa conscientização, mesmo, dela tomar o corpo como um todo [...] (p. 07-08).

Mota (2014) afirma que o fato de a bailarina já ter tido muitas experiências e vivências com a dança e o movimento (tais como: balé clássico, jazz e contato/improvisação) colaborou para a desarticulação corporal, a exploração do espaço e do gesto improvisado e o processo criativo do espetáculo. Para que novas conexões/experimentações coreográficas também pudessem ser criadas, além da experiência da própria bailarina, a direção, o preparador corporal e a coreógrafa procuraram pesquisar outras possibilidades de movimentos.

As cenas foram pensadas também para que pudessem ser contempladas e vivenciadas pela plateia com deficiência visual, explorando-se com mais atenção, por exemplo, as nuances de sonoridade. Os integrantes com deficiência visual da plateia participaram, além disso, de outros momentos da pesquisa, por meio de alguns encontros com a equipe de trabalho durante o processo de criação do espetáculo. Em tais momentos, os deficientes visuais que faziam parte da plateia puderam conhecer o processo criativo e algumas das técnicas da dança, contribuindo também para a construção cênica. No estudo, Mota (2014) traz o depoimento de dois integrantes da plateia com deficiência visual sobre um dos encontros:

[...] Percebi vários movimentos, não nítidos, mas eu percebi, assim: nascimento, vida, morte e vida, foi o que eu entendi. [...] de nascimento percebi que nascia uma criança, vida é os movimentos que ela fazia e morte quando eu escutei o som de balão que parece tiro. E depois teve vida com outros movimentos pra terminar a encenação. Percebi sons de pisadas em folhas secas, o fluido da água, os apitos, o guizo de uma cobra envolvendo o corpo dela. Tinha um corpo uma hora mais tenso, outra hora mais mole. Percebi movimentos sofridos [...]. (Roseli Ferreira, depoimento cedido em 3 de dezembro de 2012).

(...)

[...] tem algumas coisas que facilitaram, foi muito bom, pela audição e visualmente também deu pra perceber. Foi muito legal o barulho da cobrinha, muito legal essa ideia de colocar um instrumento pra parecer mesmo o som da cobra. . . . quando ela estoura os balões faz a gente ficar mais atento no que está acontecendo, dá pra entender melhor, quando estoura os três 
balões dá pra entender que é o fim da criança... (Karina Pinheiro, depoimento cedido em 3 de dezembro de 2012). (p. 11)

Mota (2014) aponta como conclusões e benefícios do estudo a conexão que foi estabelecida com a plateia com deficiência visual no processo de experimentação coreográfica, a construção coletiva de uma obra feita pela equipe em consonância com a bailarina participante do espetáculo e a ampliação das possibilidades oferecidas pela música. Como explica a autora, a elaboração do espetáculo e a presença do público formado por pessoas com deficiência visual em várias etapas dessa elaboração, incluindo a apresentação final, permitiu que houvesse o desenvolvimento de processos criativos e a ampliação das possibilidades de entendimento desses processos.

\section{CONSIDERAÇÕES FINAIS}

Podemos notar, a partir das pesquisas elencadas neste artigo, que, neste período de 20 anos, os trabalhos que articulam os temas dança e deficiência visual têm crescido entre as publicações brasileiras. Percebemos que os estudos conduzidos neste período, em grande parte, ainda estão direcionados primordialmente para as habilidades motoras, espaciais e de locomoção que a dança proporciona para a pessoa com deficiência visual, além de aspectos sociais, psíquicos e do aumento da autoestima e da inclusão social, tais como os realizados por Figueiredo, Tavares e Venâncio (1999a, 1999b); Golin (2002); Valla, Porto e Tolocka (2006); Silva, Ribeiro e Rabelo (2008); Rocha e Lima (2010, 2011, 2012); Romão (2011); Zaniboni e Rodrigues (2013); Francisco (2013); e Perez et al. (2013).

Os estudos que se direcionam para as habilidades motoras, espaciais e de locomoção contribuem significativamente para o debate. Podemos apontar, no entanto, que há estudos que vêm avançando nas discussões sobre dança e deficiência, a partir das discussões para além dos benefícios físicos, sociais e psíquicos da dança para a pessoa com deficiência visual. Esses estudos são aqueles que versam sobre a profissionalização dos(as) bailarinos(as). Embora alguns estejam mais voltados para as discussões sobre técnicas e especificidades da dança, também apresentam outras discussões sobre o tema, como os conduzidos por Freire (1999, 2000, 2004, 2004/2005, entre outros), Bianchini (2011), Mayca (2008), Melo (2010), Almeida (2012), e Mota (2014).

Consideramos importante observar que poucos estudos abordaram a importância da arte enquanto experiência estética e catártica - para as pessoas com deficiência visual, buscando compreender como a dança transformou os sujeitos que a vivenciaram. Nesse sentido, consideramos que os futuros estudos sobre dança e deficiência visual devem, além das análises e das conclusões dos benefícios alcançados, aprofundar as questões que problematizam a dança-ofício, estesia e arte, o que implica estudar o público, a emoção e o processo criativo. 


\section{REFERÊNCIAS}

ALMEIDA, R. M. F. Não ver e ser visto em dança: análise comparativa entre o Potlach Grupo de Dança e a Associação/Cia. de Ballet de Cegos. 2012. 105f. Dissertação (Mestrado em Artes) - PósGraduação em Artes da Escola de Belas Artes, Universidade Federal de Minas Gerais, Minas Gerais. 2012. Disponível em: < http://www.bibliotecadigital.ufmg.br/dspace/handle/1843/JSSS8ZZNLD>. Acesso em: 24 fev. 2017.

BIANCHINI, F. C. O Ballet Clássico para Deficientes Visuais: Método Fernanda Bianchini. 2011. 98f. Dissertação (Mestrado em Distúrbios do Desenvolvimento) - Pós-graduação em Distúrbio do Desenvolvimento, Universidade Presbiteriana Mackenzie, São Paulo. 2011.

BRASIL. Lei no 13.146, de 6 de julho de 2015. Institui a Lei Brasileira de Inclusão da Pessoa com Deficiência (Estatuto da Pessoa com Deficiência). Diário Oficial [da] República Federativa do Brasil. Disponível em: <http://www.planalto.gov.br/ccivil_03/_ato20152018/2015/lei/113146.htm>. Acesso em: 14 dez. 2017.

CAZÉ, Clotildes Maria de Jesus Oliveira; Oliveira, Adriana da Silva (2008). Dança além da visão: Possibilidades do corpo cego. Pensar a Prática, v. 11, n. 3, p. 293-302. Disponível em: < https://www.revistas.ufg.br/fef/article/view/3592/4263>. Acesso em: 22 out. 2018.

DINIZ, Debora. O que é deficiência. São Paulo: Brasiliense, 2007.

DINIZ, Debora; BARBOSA, Lívia; SANTOS, Wederson Rufino dos. Deficiência, direitos humanos e justiça. Sur. Revista Internacional de Direitos Humanos, São Paulo, v. 6, n. 11, p. 64-77, 2009. Disponível em: $<$ http://www.scielo.br/scielo.php?script=sci_arttext\&pid=S1806$64452009000200004 \& \operatorname{lng}=\mathrm{en} \& n \mathrm{~nm}=\mathrm{iso}>$. Acesso em 22 out. 2018.

FIGUEIREDO, V. M. C.; TAVARES, M. C. G. C. F.; VENÂNCIO, S. Olhar para o corpo que dança: um sentido para a pessoa portadora de deficiência visual. Movimento, n. 11, p. 65-73, 1999a. Disponível em: <http://seer.ufrgs.br/index.php/Movimento/article/view/2487/1136>. Acesso em: 15 fev. 2017.

FIGUEIREDO, V. M. C.; TAVARES, M. C. G. C. F.; VENÂNCIO, S. Uma reflexão sobre a pessoa portadora de deficiência visual e a dança. Motrivivência, n. 12, p. 213-220, 1999b. Disponível em: $<$ https://periodicos.ufsc.br/index.php/motrivivencia/article/view/14477>. Acesso em: 15 fev. 2017.

FRANCISCO, M. T. Dança Arquetípica e Biodanza - Pesquisa Qualitativa Participativa Contínua. Pensamento Biocêntrico, n. 20, p. 19-44, jul./dez. 2013. Disponível em: $<$ http://www.biodanzahoy.cl/revista/pensamento_biocentrico_20.pdf $>$. Acesso em: 16 fev. 2017. 
FREIRE, I. M. Compasso ou Descompasso: a pessoa diferente no mundo da dança. Ponto de Vista, v. 1, n. 1, p. 81-84, jul./dez. 1999. Disponível em:

$<$ https://periodicos.ufsc.br/index.php/pontodevista/article/viewFile/1524/1535>. Acesso em: 15 fev. 2017.

FREIRE, I, M. Dança-educação e a resignificação do conceito de movimento para pessoas nãovisuais. In: III SEMINÁRIO PESQUISA EM EDUCAÇÃO REGIÃO SUL, 2000, Porto Alegre. Anais... Rio Grande do Sul, 2000, p. 01-19. Disponível em: <http://docplayer.com.br/11232041Danca-educacao-e-a-resignificacao-do-conceito-de-movimento-para-pessoas-nao-visuais.html $>$. Acesso em: 16 dez. 2017.

FREIRE, I. M. A apreciação da dança pelas pessoas não-visuais: uma análise preliminar. In: LISBÔA, M. R. A.; MALUF, S. W. (Eds.) Gênero, cultura e poder. Florianópolis: Mulheres, 2004, p. 17-27.

FREIRE, I. M. Na dança contemporânea, cegueira não é escuridão. Ponto de Vista: revista de educação e processos inclusivos, n. 6/7, p. 57-78, 2004/2005. Disponível em:

$<$ https://periodicos.ufsc.br/index.php/pontodevista/article/view/1152/1467>. Acesso em: 25 jan. 2017.

GOLIN, A. F. Dança e movimento: um significado para a pessoa portadora de deficiência visual. Nossos Meios, p. 01-07, 2002.

MAYCA, F. G. Imagens e Imaginação: O Julgamento Estético no Potlach Grupo de Dança. 2008. 135f. Dissertação (Mestrado em Educação) - Pós-Graduação do Centro de Ciências da Educação, Universidade Federal de Santa Catarina, Florianópolis. 2008. Disponível em:

$<$ https://repositorio.ufsc.br/handle/123456789/91509>. Acesso em: 05 jan. 2017.

MELO, L. R. S. Um outro olhar sobre a dança: o gesto como comunicação e objeto de corporeidade, a partir da expressão artística da dança dos bailarinos não-videntes do projeto "Passos para Luz". In: III Congresso Norte-brasileiro de Ciências do Esporte, dez. 2010, Castanhal e Belém. Anais... Pará, 2010, p. 01-09. Disponível em:

$<$ http://congressos.cbce.org.br/index.php/3conceno/3conceno/paper/view/3951>. Acesso em: 27 jan. 2017.

MOTA, M. A. O Seguinte Olhar: Processo Criativo em Dança com uma Bailarina Deficiente Visual. In: II Congresso Internacional da Federação de Arte/Educadores/XXIV Congresso Nacional da Federação de Arte/Educadores do Brasil, nov. 2014, Ponta Grossa. Anais... Paraná, UEPG, p. 0114. Disponível em $<$ http://www.isapg.com.br/2014/confaeb/down.php?id=435\&q=1 $>$. Acesso em: 03 jan. 2017. 
PEREZ, S. S. et al. Inserção do deficiente visual na dança. In: VIII Encontro da Associação Brasileira de Pesquisadores em Educação Especial, nov. 2013, Londrina. Anais... Paraná, UEL, p. 790-198. Disponível em:

$<$ http://www.uel.br/eventos/congressomultidisciplinar/pages/arquivos/anais/2013/AT01-2013/AT01073.pdf>. Acesso em: 24 jan. 2017.

ROCHA, D. D.; LIMA, M. D. Dançando a corporeidade da pessoa com deficiência visual: um relato de experiência a partir de pesquisa ação. In: VII Seminário do Ensino de Arte do Estado de Goiás, 2010, Goiânia. Anais... Goiás.

ROCHA, D. D.; LIMA, M. D. Simplesmente corpo: um olhar para o corpo-sujeito com deficiência visual que dança. In: XVII Congresso Brasileiro de Ciências do Esporte/IV Congresso Internacional de Ciências do Esporte, set. 2011, Porto Alegre. Anais... Rio Grande do Sul, ESEF/UFRGS. Disponível em: <http://congressos.cbce.org.br/index.php/conbrace2011/2011/paper/view/3436>. Acesso em: 15 jan. 2017.

ROCHA, D. D.; LIMA, M. D. A dança e a pessoa com deficiência visual: desvendando caminhos e possibilidades de uma proposta educacional. In: M. C. Saraiva, N. D. Kleinubing. (Eds.). Dança: diversidade, caminhos e encontros. Jundiaí: Paco Editorial. 2012.

ROMÃO, T. S. Ampliação de movimentos na dança circular com pessoas com deficiência visual. 2011, 148f. Dissertação (Mestrado) - Pós-graduação em Artes Cênicas, Universidade Federal do Rio Grande do Norte, Natal. 2011. Disponível em:

$<$ https://repositorio.ufrn.br/jspui/handle/123456789/12444>. Acesso em: 22 jan. 2017.

SANTOS, Wederson. Pessoas com deficiência: nossa maior minoria. Physis: Revista de Saúde Coletiva, v. 18, n. 3, p. 501-519, set. 2008. Disponível em:

$<$ http://www.scielo.br/scielo.php?pid=S0103-73312008000300008\&script=sci_abstract\&tlng=pt $>$. Acesso em: 14 dez. 2017.

SANTOS, W.; DINIZ, D.; PEREIRA, N. (2010). Deficiência e Perícia Médica: Os contornos do grupo. In: MEDEIROS, M.; DINIZ, D.; BARBOSA; L. (Eds.), Deficiência e Igualdade, 153-173. Brasília: Letras Livres e Editora UnB.

SASSAKI, Romeu Kazumi. Inclusão: construindo uma sociedade para todos. Rio de Janeiro: WVA, 1997.

SILVA, C. A. C.; RIBEIRO, G. M.; RABELO, R. J. A influência da dança no equilíbrio corporal de deficientes visuais. Movimentum - Revista Digital de Educação Física, n. 3, v. 1, p. 1-8, fev./jul. 2008. Disponível em:

$<$ https://www.unilestemg.br/movimentum/Artigos_V3N1_em_pdf/movimentum_v3_n1_silva_cristi ane_ribeiro_graziele_2_2007.pdf $>$. Acesso em: 26 fev. 2017. 
VALLA, D. C. R. M.; PORTO, E. T. R.; TOLOCKA, R. E. Deficiência visual e sapateado: possibilidade de aprendizagem e busca da vivência da corporeidade. Revista Digital efdeportes.com., n. 99, ago. 2006. Disponível em: <http://www.efdeportes.com/efd99/visual.htm >. Acesso em: 25 fev. 2017.

VIGOTSKI, L.S. Fundamentos de Defectología. Moscou: Editorial Pedagógica, 1997. 391p. ZANIBONI, Lilian Fátima; RODRIGUES, José Augusto. Dança de salão: inclusão social e realização pessoal. Conexões, Campinas, SP, v. 11, n. 2, p. 223-239, jun. 2013. ISSN 1983-9030. Disponível em: <http://periodicos.sbu.unicamp.br/ojs/index.php/conexoes/article/view/8637625>. Acesso em: 27 fev. 2017.

$\begin{array}{ll}\text { Histórico } & \text { Recebido em: 3-3-2017 } \\ & \text { Revisado em: 12-2-2018 } \\ & \text { Aceito em: } 12-5-2018\end{array}$

